\title{
SHORT COMMUNICATION Criterion values for urine-specific gravity and urine color representing adequate water intake in healthy adults
}

\author{
ET Perrier, JH Bottin, M Vecchio and G Lemetais
}

Growing evidence suggests a distinction between water intake necessary for maintaining a euhydrated state, and water intake considered to be adequate from a perspective of long-term health. Previously, we have proposed that maintaining a $24-\mathrm{h}$ urine osmolality $\left(U_{\mathrm{Osm}}\right)$ of $\leqslant 500 \mathrm{mOsm} / \mathrm{kg}$ is a desirable target for urine concentration to ensure sufficient urinary output to reduce renal health risk and circulating vasopressin. In clinical practice and field monitoring, the measurement of $U_{\text {Osm }}$ is not practical. In this analysis, we calculate criterion values for urine-specific gravity $\left(U_{\mathrm{SG}}\right)$ and urine color $\left(U_{\mathrm{Col}}\right)$, two measures which have broad applicability in clinical and field settings. A receiver operating characteristic curve analysis performed on 817 urine samples demonstrates that a $U_{S G} \geqslant 1.013$ detects $U_{\text {Osm }}>500 \mathrm{mOsm} / \mathrm{kg}$ with very high accuracy (AUC 0.984), whereas a subject-assessed $U_{\text {Col }} \geqslant 4$ offers high sensitivity and moderate specificity (AUC 0.831) for detecting $U_{\text {Osm }}>500 \mathrm{~m}$ Osm/kg.

European Journal of Clinical Nutrition (2017) 71, 561-563; doi:10.1038/ejcn.2016.269; published online 1 February 2017

\section{INTRODUCTION}

Water is essential to life, represents the largest single nutrient in terms of intake, and must be replenished daily through food and fluid consumption. Adequate intakes have been established based upon population median data. However, adequate intakes are not linked to specific health outcomes, and daily water needs are highly individual and depend upon environment, activity, diet and other factors. Thus, a dietary reference value for the general population is unlikely to have much relevance for the individual. Various biomarkers of urine concentration allow for individual-level daily hydration monitoring. Specifically, urine osmolality $\left(U_{\mathrm{Osm}}\right)$ is the most precise, non-invasive biomarker available to evaluate the 24-h hydration process, as it represents the net sum of water gains, losses and neuroendocrine responses that act to maintain body water homeostasis, and responds rapidly to changes in daily water intake. ${ }^{1,2}$ Recently, we proposed a $24-\mathrm{h} U_{\text {Osm }}$ of $\leqslant 500 \mathrm{mOsm} / \mathrm{kg}$ as a reasonable target for urine concentration, reflecting sufficient total water intake to compensate daily losses, reduce circulating vasopressin and ensure sufficient urinary output to reduce the risk of some renal health outcomes. ${ }^{3}$ However, one limitation to a target based upon $U_{\mathrm{Osm}}$ is that it is not easily measured day to day; moreover, clinicians, coaches and dietitians lack the possibility to measure $U_{\text {Osm }}$ within their practices or in the field, limiting its utility as a hydration monitoring tool for the larger population. Two alternate methods for measuring urine concentration with greater clinical and field applicability are urine-specific gravity $\left(U_{\mathrm{SG}}\right)$, which can easily be measured by clinicians, and urine color $\left(U_{\text {Col }}\right)$, which may be self-assessed. To date, no criterion values for $U_{\mathrm{SG}}$ nor $U_{\text {Coll }}$ corresponding to a $U_{\text {Osm }}$ of $500 \mathrm{mOsm} / \mathrm{kg}$, have been published. Thus, the objective of this analysis was to calculate the criterion values for $U_{\mathrm{SG}}$ and subject-assessed $U_{\text {Col }}$, which would have the best diagnostic accuracy for identifying $U_{\text {Osm }}>500 \mathrm{mOsm} / \mathrm{kg}$.

\section{METHODS}

Eighty-two healthy French adults $(23.6 \pm 2.9$ years; $22.2 \pm$ $1.5 \mathrm{~kg} / \mathrm{m}^{2} ; 41$ women) provided informed consent (CPP Est-III, Nancy, France) and collected all individual voids produced over 1-4 consecutive days as part of a larger study (NCT02044679). On collection days, subjects woke up before 0700 hours, voided and discarded this first morning sample. Subsequent voids were collected in individual, clear plastic containers, including the first morning void of the following morning at 0700 hours. For each void, participants self-evaluated $U_{\text {Col }}$ using Armstrong et al.'s color scale, under consistent lighting conditions. ${ }^{4}$ Once samples were returned to the laboratory, $U_{S G}$ (Pen Urine S.G.; Atago, Japan) and $U_{\text {Osm }}$ (Advanced Model 2020 Multi-Sample Osmometer; Advanced Instruments, Inc., Norwood, MA, USA) were measured.

Logistic regression curves were generated with $U_{S G}$ and $U_{\text {Col }}$ as predictor variables, and $U_{\text {Osm }}$ as a binary outcome variable, with $U_{\text {Osm }}>500 \mathrm{mOsm} / \mathrm{kg}$ defined as 'condition present', and $U_{\text {Osm }} \leqslant 500 \mathrm{mOsm} / \mathrm{kg}$ as 'condition absent'. The optimal cutoffs for $U_{\mathrm{SG}}$ and $U_{\text {Col }}$ for identifying $U_{\text {Osm }}>500 \mathrm{mOsm} / \mathrm{kg}$ were determined by receiver operating characteristic (ROC) curve analysis. We were equally interested in evaluating sensitivity (if $U_{\text {Osm }}$ is $>500 \mathrm{mOsm} / \mathrm{kg}$, how often will $U_{\mathrm{SG}}, U_{\mathrm{Col}}$ be at or above the cutoff values?) and specificity (if $U_{\text {Osm }}$ is $\leqslant 500 \mathrm{mOsm} / \mathrm{kg}$, how often will $U_{\mathrm{SG}}, U_{\mathrm{Col}}$ be below the cutoff values?); thus, our analysis favored neither sensitivity nor specificity.

\section{RESULTS}

A total of 817 urine samples were analyzed for $U_{\text {Osm }}$ and $U_{\text {SG. }}$ One sample had a missing value for $U_{\text {Col }}$ (816 samples). The mean (5th; 95th percentile) for $U_{\text {Osm }}, U_{S G}$ and $U_{\text {Col, }}$ respectively, were 436 (192; 938) mOsm/kg, $1.012(1.003 ; 1.025)$ and $4(1 ; 7)$. The ROC analysis revealed the optimal $U_{\mathrm{SG}}$ cutoff for identifying $U_{\text {Osm }}$ $>500 \mathrm{mOsm} / \mathrm{kg}$ was 1.013 (AUC 0.984), whereas the cutoff for $U_{\text {Col }}$ was 4 (AUC 0.831 ) (Figure 1). A $U_{S G}$ of $\geqslant 1.013$ offered very

Danone Research, RD 128, Palaiseau Cedex, France. Correspondence: Dr ET Perrier, Danone Research, RD 128, Palaiseau Cedex 91767, France. 
high sensitivity and high specificity; whereas a $U_{\text {Col }}$ of $\geqslant 4$ had good sensitivity and moderate specificity (Table 1 ).

\section{DISCUSSION}

Insufficient water intake or low urinary output has been associated with health outcomes, including recurrent kidney stones,

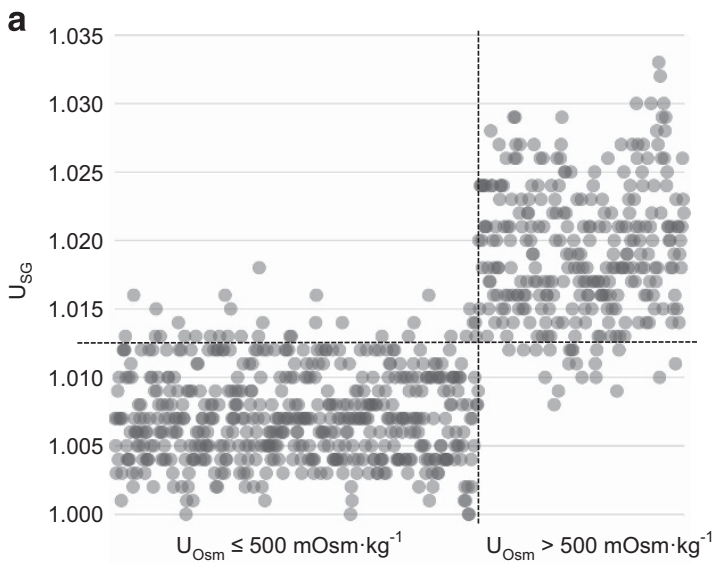

b

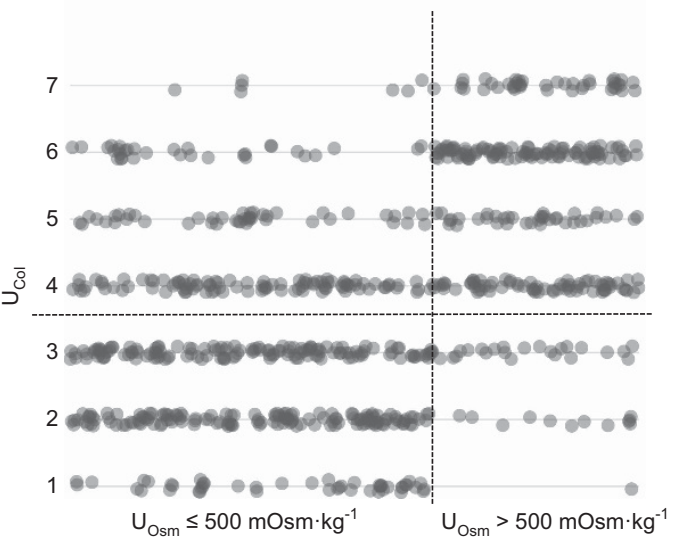

Figure 1. Distribution of (a) $U_{\mathrm{SG}}$ and (b) $U_{\mathrm{Col}}$ measures as a function of $U_{\mathrm{Osm}}$. $U_{\mathrm{SG}} \geqslant 1.013$ offered both very high sensitivity and high specificity to detect $U_{\text {Osm }}>500 \mathrm{mOsm} / \mathrm{kg}$. $U_{\text {Col }} \geqslant 4$ provided good sensitivity and moderate specificity. increased risk of renal insufficiency and impaired glucose regulation. $^{5-7}$ A $U_{\text {Osm }}$ of less than $500 \mathrm{mOsm} / \mathrm{kg}$ has been proposed as a reasonable target for 'optimal hydration', 'but $U_{\text {Osm }}$ is not a practical field measure and to date, no corresponding values for $U_{S G}$ nor $U_{\text {Col }}$ have been published. In this analysis, we demonstrate that both $U_{\mathrm{Col}}$ and $U_{\mathrm{SG}}$ may be used as surrogates for $U_{\text {Osm }}$ to identify individuals above or below the $500 \mathrm{mOsm} / \mathrm{kg}$ target. $U_{S G}$ is both sensitive and specific, suggesting its utility for health care professionals and clinicians within their daily practice. Subject-assessed $U_{\text {Col }}$ demonstrated good sensitivity and moderate specificity. To our knowledge, this is the first subject-selfassessment of $U_{\text {Col }}$ by healthy adults, confirming $U_{\text {Col }}$ as a practical field measure with utility in day-to-day individual hydration monitoring.

These findings confirm and build upon recent work by McKenzie et al., ${ }^{8}$ who validated a $U_{\text {col }}$ of 4 or greater as a practical field measure for detecting $U_{\text {Osm }}>500 \mathrm{mOsm} / \mathrm{kg}$ in pregnant and breastfeeding women. Moreover, our $U_{\mathrm{SG}}$ and $U_{\mathrm{Col}}$ criterion values for detecting $U_{\text {Osm }}>500 \mathrm{mOsm} / \mathrm{kg}$ (1.013 or higher, and 4 or higher, respectively) are similar to those first published by Armstrong et al., who reported that in a sample of young, mostly male college students, for a sample with $U_{\text {Col }}$ of 3 or lower, the respective mean $U_{\mathrm{Osm}}$ and $U_{\mathrm{SG}}$ were less than $520 \mathrm{mOsm} / \mathrm{kg}$ and $1.014 .^{4}$

Finally, the $U_{\mathrm{SG}}$ and $U_{\text {Col }}$ criterion values for $U_{\mathrm{Osm}}$ $<500 \mathrm{mOsm} / \mathrm{kg}$ continue to build upon a new but growing distinction between the hydration state (acute dehydration), the upper limit of euhydration and being well-hydrated from the perspective of disease risk. Cheuvront et al.'s decision levels for detecting dehydration (body mass loss of $3.7 \pm 1.0 \%$ ) based upon $U_{\text {Osm }}$ and $U_{\text {SG }}$ were $1018 \pm 245 \mathrm{mOsm} / \mathrm{kg}$ and $1.028 \pm 0.006$, respectively, ${ }^{9}$ whereas an acceptable euhydration cutoff has been reported as $<700^{10}$ to $<830^{1} \mathrm{mOsm} / \mathrm{kg}$ for $U_{\text {Osm }}$ and $<1.020$ for $U_{\mathrm{SG}}{ }^{10}$ This paper complements the existing literature by providing calculated cutoff values for $U_{\text {SG }}$ $(\geqslant 1.013)$ and self-assessed $U_{\text {Col }}(\geqslant 4)$ that accurately detect $U_{\text {Osm }}>500 \mathrm{mOsm} / \mathrm{kg}$. Given the recent associations between low water intake, low urine output and some renal and metabolic health outcomes, ${ }^{5-7}$ we propose remaining below these cutoff values as a target for being well or optimally hydrated.

\section{CONFLICT OF INTEREST}

The authors declare no conflict of interest.

Table 1. Urine samples classified according to $U_{\mathrm{Osm}}, U_{S G}$ and $U_{\text {Col }}$ values; followed by metrics from ROC analysis

\begin{tabular}{|c|c|c|c|c|c|c|c|}
\hline \multirow{2}{*}{$\begin{array}{l}\text { Criterion value for test } \\
\text { measure }\left(U_{S G}, U_{C o l}\right)\end{array}$} & \multicolumn{2}{|c|}{ Reference measure $\left(U_{\text {Osm }}\right)$} & \multicolumn{5}{|c|}{ Metrics from ROC analysis ${ }^{\mathrm{a}}$} \\
\hline & $\begin{array}{l}U_{\text {Osm }}>500 \\
(\mathrm{n}=295)\end{array}$ & $\begin{array}{c}U_{\text {Osm }} \leqslant 500\left(\mathrm{n}=521, U_{\text {Col }}\right) \\
\left(\mathrm{n}=522, U_{S G}\right)\end{array}$ & Sensitivity & Specificity & Accuracy & PPV & $N P V$ \\
\hline$U_{S G} \geqslant 1.013(n=307)$ & 275 & 32 & 0.984 & 0.932 & 0.939 & 0.896 & 0.961 \\
\hline$U_{\mathrm{SG}}<1.013(n=510)$ & 20 & 490 & & & & & \\
\hline$U_{\text {Col }} \geqslant 4(n=445)$ & 259 & 186 & 0.878 & 0.643 & 0.728 & 0.582 & 0.903 \\
\hline$U_{\text {Col }}<4(n=371)$ & 36 & 335 & & & & & \\
\hline
\end{tabular}




\section{ACKNOWLEDGEMENTS}

The authors are employees of Danone Research, who funded this study.

\section{REFERENCES}

1 Manz F, Wentz A. 24-h hydration status: parameters, epidemiology and recommendations. Eur J Clin Nutr 2003; 57(Suppl 2): S10-S18.

2 Perrier ET, Armstrong LE, Daudon M, Kavouras S, Lafontan M, Lang F et al. From state to process: defining hydration. Obes Facts 2014; 7(Suppl 2): 6-12.

3 Perrier ET, Buendia-Jimenez I, Vecchio M, Armstrong LE, Tack I, Klein A. Twentyfour-hour urine osmolality as a physiological index of adequate water intake. Dis Markers 2015; 2015: 231063

4 Armstrong LE, Maresh CM, Castellani JW, Bergeron MF, Kenefick RW, LaGasse KE et al. Urinary indices of hydration status. Int J Sport Nutr 1994; 4: 265-279.

5 Borghi L, Meschi T, Amato F, Briganti A, Novarini A, Giannini A. Urinary volume, water and recurrences in idiopathic calcium nephrolithiasis: a 5-year randomized prospective study. J Urol 1996; 155: 839-843.

6 Clark WF, Sontrop JM, Macnab JJ, Suri RS, Moist L, Salvadori M et al. Urine volume and change in estimated gfr in a community-based cohort study. Clin J Am Soc Nephrol 2011; 6: 2634-2641.
7 Roussel R, Fezeu L, Bouby N, Balkau B, Lantieri O, Alhenc-Gelas F et al. Low water intake and risk for new-onset hyperglycemia. Diabetes Care 2011; 34 2551-2554.

8 McKenzie AL, Munoz CZ, Ellis LA, Perrier ET, Guelinckx I, Klein A et al. Urine colour as an indicator of urine concentration in pregnant and lactating women. Eur $J$ Nutr; epub ahead of print 16 November 2015; doi:10.1007s00394-015-1085-9.

9 Cheuvront SN, Sawka MN. Hydration assessment of athletes. Sports Sci Exchange 2005; 18: 1-6.

10 Sawka MN, Burke LM, Eichner ER, Maughan RJ, Montain SJ, Stachenfeld NS. American College of Sports Medicine position stand. Exercise and fluid replacement. Med Sci Sports Exerc 2007; 39: 377-390.

(c) (i) $\odot$ This work is licensed under a Creative Commons Attribution NonCommercial-NoDerivs 4.0 International License. The images or other third party material in this article are included in the article's Creative Commons license, unless indicated otherwise in the credit line; if the material is not included under the Creative Commons license, users will need to obtain permission from the license holder to reproduce the material. To view a copy of this license, visit http:// creativecommons.org/licenses/by-nc-nd/4.0/

(c) The Author(s) 2017 